\title{
Accounting for structure and agency in 'close-up' research on teaching, learning and assessment in higher education.
}

\author{
Paul Ashwin \\ Department of Educational Research, Lancaster University, Lancaster, LAl 4YD
}

\begin{abstract}
This paper focuses on examining research into teaching, learning and assessment (TLA) in higher education in terms of structure and agency. It argues that although issues of structure and agency are seen as crucial in social theory, they are very little discussed in research into TLA in higher education and that a consideration of structure and agency raises some important questions about this research and the quality of the explanations that it generates. It is therefore time to reconsider this research from the standpoint of structure and agency so that more sophisticated approaches to researching, and generating explanations of, teaching, learning and assessment in higher education can be developed.
\end{abstract}

\section{Key Words}

Agency, structure, teaching, learning, assessment, higher education

\section{Introduction}


In this paper, I argue that there has been very little focus on issues of structure and agency in 'close-up' research into teaching, learning and assessment (TLA) in higher education. The term 'teaching, learning and assessment' is used here to refer to the interactions and processes in which academics and students engage in relation to the curricula that make up higher education programmes. The intention is to focus on examining the educational significance of TLA in higher education. There are many studies of aspects of TLA that do not view them as educational processes but rather as examples of processes of other types. For example, Bourdieu and Passeron (1977) and Bourdieu et al (1996) see them as processes of legitimation and reproduction of existing social relations. In fact, from their perspective, to see the purposes of education in educational terms represents a misrecognition of their objective purposes.

It should also be noted that my argument is focused on research into TLA in higher education. There are many studies of TLA in school education that attempt to address issues of structure and agency. They date back to the early 1970s, especially those from the perspective of interactionist ethnography (see Hammersley 1999 for a brief history of this research in schools). Equally, it should be noted that the research I will discuss is largely from Europe and Australia. As Tight (2007) notes this research is largely separate from the research in North America.

In the paper, I first set out, in general terms, what is at stake in debates around 'structure and agency' before defining my focus on them in relation to TLA in higher education. I illustrate how the absence of considerations of structure and agency in what might be considered to be the mainstream of research into TLA in higher 
education limits its explanatory power. Further, I argue that as well as offering more complete explanations, a consideration of issues of structure and agency also highlights a number of weaknesses in research into TLA in higher education. In conclusion, I suggest that an explicit focus on issues of structure and agency can help to improve the quality explanations generated through close-up research in TLA in higher education.

\section{What is at stake in structure and agency?}

Debates around structure and agency raise a series of very significant questions: How much are individuals free to decide on their own actions and how much are they constrained by the social settings in which they operate? Are explanations of educational phenomena to be found at the micro level of the individual or at the macro societal level? To what extent are educational institutions stable entities or to what extent can they be changed by the actions of individuals? How much can educational theory predict educational practice and how much does practice define theory?

These questions give an initial indication of the sorts of issues that are the focus of this paper. In different ways each of these questions relate to the appropriate level at which educational explanations should be situated. For some, an educational interaction is explained when we have evidence of actors' intentions. For others, it is only explained when we can show how that educational interaction is structured by its wider social context. 
Such issues have been widely discussed in debates around social theory generally (for example Giddens, 1984; Bourdieu; 1992; Archer; 1995; Layder; 1997; Sibeon; 2004). Indeed, for some it is the central problem in social explanations (Mouzelis; 1995), whilst other researchers argue that the ability of their conceptual approach to account for both structure and agency is an indicator of its explanatory power (for example see Byrne; 1998; Flyberg; 2001). However, in the field of research into TLA in higher education these issues are hardly discussed. My argument in this paper is that explanations of the educational significance of TLA need to focus on both individual's intentions and on the ways in which these intentions are structured by institutions and wider social structures. In doing so, my intention is not to spell out a fully formed interpretation of how structural and agentic factors impact on TLA interactions in higher education but rather to argue that an explicit consideration of these issues is vital if this research is to develop more complete explanations of such interactions.

Whilst it is beyond the scope of this paper to offer a complete argument for a particular relation between structure and agency, it is important to give an initial indication of how structure and agency are viewed specifically in relation to TLA in higher education. This is because it will have some bearing on my argument for what considering issues around structure and agency can offer research in this area. My intention in thinking about structure and agency in TLA is to try to develop more complete explanations of these situations. It is not, as is the case in some ethnographic studies, to view these single situations as microcosms that exemplify universal social processes (see Hammersley, 1992 pp.16-19 for an exposition and critique of this approach). From my perspective social structure is part of day-to-day TLA 
interactions as well as of the categories and concepts that are used to think about them (see Zimmerman and Boden, 1991 for a discussion of this view of the relationship between structure and agency). Thus my interest is in focusing on the ways in which the meanings attributed to particular TLA interactions in higher education by participants in them (both students and academics) are related to issues of identity, the disciplinary and institutional contexts in which they take place as well as their wider socio-political context. This is in contrast to approaches which examine aspects of structure and agency by relating different types of studies, those located at a structural level and those located at the level of social action, as Knight et al do in their study of assessment and reporting practices in higher education in this issue, or combining different types of data within a single study, as Dibbens (2006) does in relating her interview data to data on her interviewees social class and as Suellen Shay does, in this issue, in her study of assessment as a social practice.

This means that my focus is on examining particular TLA interactions on the assumption that the relation between structure and agency shifts over time and between situations: that it is situationally contingent. Studying specific incidents can give us a sense of a particular configuration of structural and agentic factors, configurations that we can compare over time and between situations.

Finally, in this view of the relationship between structure and agency, structural and agentic factor act on what Hymes (1995, p.2) calls the "cognitive unconscious". That is to say, as well as affecting them in ways of which they are conscious, these factors can influence agents in ways of which they are unaware including the categories and concepts that they use to structure their interpretation of particular situations. Thus an 
individual's biography, the institutional setting, the historical moment, and wider social-political factors can impact on TLA situations in ways that are outside of the awareness of academics and students and can also impact on the work researchers in studying TLA . This is a feature of Bourdieu's (1977) notion of habitus, which offers a fairly structuralist interpretation of the notion of the cognitive unconscious, in which individuals' perceptions of social fields are structured in ways that are largely invisible to the agents who operate within them.

\section{Some comments on 'mainstream' research into teaching, learning and assessment in higher education from the perspective of structure and agency}

By the 'mainstream' research into TLA in higher education I mean research from the 'approaches to learning' perspective. This research has dominated research in this area (Webb, 1997; Haggis; 2003; McLean; 2006). It focuses on examining the relations between students' and teacher's perceptions of their teaching and learning contexts and how these relate to the way in which they approach their teaching and learning activities as well as the outcomes of these activities This perspective has consistently found that variation in students' and academics' perceptions of their teaching and learning environment relate to variations in the quality of teaching and learning outcomes(for useful summaries of this research see Prosser and Trigwell, 1999; Richardson, 2005).

In examining this approaches to learning research in terms of structure and agency, there are two major problems with the explanations that are offered. First, because this research approach is focused on students' and teachers' perceptions of teaching 
and learning environments, they are firmly rooted in considerations of agency. Anything that operates outside of these perceptions is bracketed outside of explanations offered. This is reminiscent of Apple's (1979) criticism of phenomenology that it "inclines us to forget that there are objective institutions and structures 'out there' that have power, that control our lives and our very perception" (p.140).

Second, 'approaches to learning' research is only focused on academics and students as teachers and learners. It is only those aspects of teaching and learning situations that are directly related to teaching and learning that are considered relevant within these research studies. As a result this perspective focuses on 'disembodied' learners and teachers and tends to underplay the importance of their identities and power relations in teaching and learning interactions. This means that academics, students and their institutional contexts cease to have a history and that the explanatory framework is ahistorical. Thus it is unsurprising that, despite the huge changes that have taken place in, for example, the composition of the student body, student: staff ratios, and the number and type of universities since the approaches to learning approach was first developed in the 1970s (for example, see Ashwin, 2006a), its basic explanation of TLA interactions has remained largely unchanged.

These problems have led to increasing criticism of this research. So, for example, in work in the area of academic literacies (see Lea and Street, 1998; Jones et al; 1999; Lillis; 2001) and other research which focuses on teaching and learning as social practices (for example see Mann; 2000; Trowler and Cooper; 2002; Jones et al, 2005; Trowler, 2005), there has been an emphasis on the importance of the identities and 
institutional locations of students and academics in helping to shape teaching and learning interactions. However, most of this research has not been discussed in terms of structure and agency. Whilst there are some notable exceptions to this (Trowler, 1998; Fanghanel 2004, and in this issue; Shay, 2005; McLean, 2006), none explicitly discuss what it means to attempt to account for structure and agency in researching TLA in higher education. This is a pity because thinking about how we account for structure and agency raises some fundamental conceptual and methodological issues that, whilst routinely discussed in textbooks on social science methodology (for example Silverman, 2001), are largely ignored in research into TLA in higher education.

These issues are related to the relationship between different units of analysis; the conceptualisation of the relationship between teaching, learning and assessment; the research methods that are used; and the accounts of the origins of research questions and approaches to data analysis that are given in research into TLA in higher education. These issues are directly related to the initial conceptualisation of structure and agency that I outlined earlier. Viewing the relationship between structure and agency as situationally contingent raises issues about the relationship between units of analysis and between teaching, learning and assessment; whilst the impact of agentic and structural factors on the cognitive unconscious raises issues about the research methods that are used to generate data in TLA research as well as the accounts given of the origins of research questions and approaches to data analysis. In the rest of the paper, I examine each of these issues in turn. 


\section{Some implications for research into TLA of viewing the relationship between structure and agency as situationally contingent}

\subsection{The relationship between units of analysis in research into teaching, learning and assessment in higher education}

The focus I outlined earlier on examining particular TLA interactions on the assumption that the relation between structure and agency shifts over time and between situations, raises questions about how the relationship between different units of analysis is conceived in research into TLA in higher education. Specifically, it suggests that relationship between different types of units of analysis need also to be seen as situationally contingent; as an empirical question that research attempts to address. In this section, I examine the different units of analysis that are used in studying TLA in higher education and, using research into communities of practice in TLA in higher education as an example, argue that the relationship between these different units of analysis is seldom discussed or problematised in this research.

In researching TLA in higher education there are four units of analysis that are generally focused upon: academics' and students' perceptions; social practices; discourses; and systems (although it should be noted that some have argued for broad categories of types of disciplinary knowledge as important units of analysis, see Neumann, 2001; Neumann, et al 2002).

Academics' and students' perceptions of TLA in higher education are the focus of the 'approaches to learning' research, which has been discussed earlier in this article and shown, on its own, to be an insufficient unit of analysis to account for structure and agency. 
Of the other three units of analysis that are focused upon, probably the most fully explored in research into TLA in that of social practices (see Trowler, 2005 for an exposition of social practice theory and its problems in relation to teaching and learning in higher education). In undertaking research into TLA as social practices, rather than focusing on them as purely pedagogical encounters, one can consider a broad range of factors that impact on the practices that academics and students engage with in TLA situations. This is a level of analysis beyond that of individual because, as Bourdieu (1977) argues, the structures of practices are more stable than the meanings agents assign to them.

A third approach that is taken is to examine discourses in TLA interactions (for example see Boughey and Case and Marshall in this issue; Jones et al, 2005; Peters, 2005). These are significant in that they are "revealing about the social shaping of thought and the local, situational, and pragmatic organisation of conceptual thinking" (Edwards, 1993 p.213). In this way discourses provide an insight into both the social and individual aspects of TLA interactions. It is important to be clear that in this context discourse is taken to be what Bernstein (1990) calls, 'pedagogic discourses', the "social relation of transmission and acquisition" (p.7), and the focus is on how these are constituted in particular TLA interactions. This is as opposed to examining how policy discourses (e.g. Chan, 2005) or wider societal discourses play out in TLA situations (e.g. Archer at al, 2001; Read et al, 2003; Walker, 2004).

A fourth approach is to see TLA interactions as involving interactions within or between systems (for example see Fanghanel, 2004; Haggis, 2004). These systems 
can be seen in a number of ways: in terms of interacting social domains (Layder, 1997); of interacting activity systems, (Engeström, 2001); or of dynamic systems as in complexity theory (Fogel et al, 1997; Byrne 1999). These systems contain aspects of the history and biography of academics and students, and their institutional setting, which help to explain the meaning of the particular TLA interaction.

It should be noted that the differences between these accounts is in terms of what is placed in the foreground and background in the analysis rather than researchers treating perceptions, practices, discourses and systems as mutually exclusive categories. For example, in researching communities of practice (see Lave and Wenger, 1991; Wenger, 1998), some researchers emphasise individuals' perceptions of their communities of practice, as Fanghanel does in her paper in this issue. Others focus on the practice element of communities of practice. For example, Tummons' paper in this issue looks at the literacy practices that students engage in as part of a teaching training course. A third potential focus is on the community, or system, element of the community of practice, as Price (2005) does in her consideration of the extent to which module teams in a business school share their tacit knowledge about assessment. Finally, others emphasise the discourses that characterise different communities of practice, as Avis et al (2002) do in their consideration of the construction of learners in post-compulsory education and training. Each of these examples draw on notions of perceptions, social practices, discourses, and systems but in each of these cases a different concept takes centre stage and is taken as the primary unit of analysis. 
The problem is that the differences between the foci of these studies are rarely acknowledged and the assumption seems to be that the relationship between the different units of analysis is self evident and unchanging. However, from the perspective of structure and agency, this relationship becomes crucial because the focus of the explanation is on how these different factors relate in particular TLA situations. Developing an understanding of the different relationships between perceptions, practices, discourses and systems in different TLA contexts in higher education, rather than treating them as apparently self-evident and static categories, is vital if explanations of the roles different configurations of these factors play in TLA are to be developed.

Thus a focus on the relationship between structure and agency raises questions about the relationship between the different units of analysis used in research into TLA in higher education, questions that are important if higher quality explanations of such interactions are to be developed.

\subsection{The relationship between teaching, learning and assessment in higher education}

As well as raising questions about the relationship between different units of analysis in research into TLA in higher education, the assumption that the relationship between different aspects of TLA situations are situationally contingent also raises questions about the characterisation of the relationship between TLA in such research.

In much research in this area, academics and students are treated as if they are involved in separate processes. In the 'approaches to learning' perspective the 
research into students'conceptions and approaches to learning and academics' conceptions and approaches to teaching developed at different times and, in summaries of the literature (for example Prosser and Trigwell, 1999; Ramsden, 2003), they are dealt with separately. In the literature on TLA as social practices some research focuses primarily on the practices of students (for example, Tummons in this issue; Lea and Street, 1998; Mann; 2000; Lillis; 2001), whilst others are more interested in the practices of academics (for example, Fanghanel's and Shay's paper in this issue; Trowler and Cooper, 2002).

The problem with this separation of the activities of academics and students in TLA is that it can lead to the tacit assumption that, in TLA interactions, the academic teaches and assesses while the student learns and is assessed. This problem is most clearly illustrated when one focuses on specific academic tasks in which students' and academics are engaged. For example, although students' and academics' accounts of tutorials have been generated separately in the 'approaches to learning' literature (Ashwin, 2005; Ashwin 2006b), in any one tutorial there are not four separate processes going on with the tutor engaged in two activities (teaching and assessing) and the students engaged in two different activities (learning and being assessed). There is instead a single activity that involves academics and students in different aspects of teaching, learning, and assessment. An absolutely crucial factor that structures this interaction for both students and academics is the role played by the other party. So, in both students' and academics' accounts of tutorials, the role of the tutor and students is central to the understanding of what a particular tutorial means (Ashwin, 2005; Ashwin, 2006b). Thus the individual agents are not acting alone on 
their separate tasks but instead mutually condition each other's perceptions and practices.

The separation of the perceptions or social practices of academics from those of students can also have the effect of over emphasising the degree of agency that they have in determining their action because it takes attention away from the degree to which the roles of students and academics are structured by the expectations of the other and the institutional and cultural norms associated with these roles. (for example see Bourdieu and Passeron, 1977 on the extent to which academics are defined in their teaching role by their institutional location and Bourdieu et al 1994 on how they are defined by the expectations of their students).

Thus thinking about how to account for structure and agency in researching TLA in higher education, highlights the need to have a more contingent conception of how teaching, learning and assessment will be related in particular contexts. The relationship between teaching, learning and assessment becomes a question to explore in particular interactions rather than a static variable that structures the research. The limited research that has examined how the practices of students and academics relate to each other gives a good sense of the contingent nature of this relationship (see Lindberg-Sand and Olsson in this issue; Mann, 2003; Fejes et al, 2005; Jones et al, 2005). This research can play an important role in questioning assumptions about how teaching, learning and assessment are related in higher education and is important if more sophisticated explanations of these relations are to be developed.

\section{Some implications of the 'cognitive unconscious' on research into TLA in higher education}




\subsection{Generating data on teaching, learning and assessment in higher education}

The notion of the cognitive unconscious outlined earlier has implications for the data that is generated in researching TLA in higher education. In a significant proportion of research into TLA in higher education, data are generated based solely on the accounts of academics and students, usually through interviews or questionnaires or through a mixture of the two. This is the case in the 'approaches to learning' perspective where most studies either use questionnaires or interviews to generate their data (see Richardson, 2005 for a useful summary of the instruments used in different studies) but it is also true of in research into TLA in higher education from other perspectives in that research into TLA as social practices largely focuses on academics' and students' accounts of these practices (for example see Fanghanel in this issue); research into TLA discourses often focus on the discourses that students and academics use in talking about TLA (for example Case and Marshall in this issue), and research into TLA systems focus on academics and students accounts of these systems (for example, Fanghanel, 2004). The extent of this reliance on students' and academics' account is illustrated by Tight's (2003) analysis of the research published in Higher Education journals in 2000, which suggests that the vast majority ${ }^{1}$ of empirical studies focusing on teaching and learning, course design, student experience in higher education (the categories of Tight's that make up what I have called TLA in this paper) use the accounts of students and/or academics as the source of their data.

\footnotetext{
${ }^{1}$ This is based on combining Tight's (2003) categories of 'phenomenography', 'interviews' and 'multivariate', which all involve the use of data obtained by interviews or questionnaires.
} 
However, if one accepts that social structures and agentic factors can help to shape the 'cognitive unconscious', then this sole reliance on the accounts given by academics and students becomes extremely problematic. If respondents are not aware of the impact of structural and agentic factors on their experience of TLA interactions then the explanations that are generated from these accounts are likely to significantly underestimate their influence.

In response to this issues, some use the Knight and Saunders (1999) notion of dialogic interviewing to suggest that, through a reflective dialogue with a researcher, academics and students can bring these more structural and agentic factors into their consciousness (for example, see Fanghanel in this issue). However, there are two problems with this approach. First, this reflective dialogue tends to be at a fairly general level, taking the research away from a focus on particular TLA interactions. Second, because this reflection is on academics' and students' experiences it seems possible that these experiences have already been structured by the 'cognitive unconscious' in ways that distort the impact of structural and agentic factors on these experiences.

Given these problems, it is unsurprising that those who have attempted to research the relations between TLA in higher education have sought to use videos of such interactions (Mann, 2003; Jones et al, 2004) as the basis for reflection by academics and students about what is occurring. Such research methods are labour intensive and fail to solve all the issues that are attendant in accounting for structure and agency, but they do take the researcher, academics and students closer to actual TLA interactions rather than relying solely on academics' and students' accounts of these experiences. 
Concerns about the unreflective reliance on interview and questionnaire data in social science research are not new of course. For example, Bourdieu (1977, p.120) argues:

simply by bringing to the level of discourse - as one must, if one wants to study it scientifically - a practice which owes a number of its properties to the fact that it falls short of discourse ... one subjects it to nothing less than a change in ontological status the more serious in its theoretical consequence because it has every chance of going unnoticed

However, the reason to raise the issue here is that it is not often discussed in relation to research into TLA in higher education (a point made very strongly in a review of studies conducted by Kane et al, 2002). Thinking about how one might account for structure and agency in these interactions, at least poses the question of the meaning of the data that are generated in this research and the consideration of this question can only contribute to higher quality explanations of TLA in higher education.

\subsection{Accounts of the origins of research questions and approaches to data analysis in research into teaching, learning and assessment in higher education}

If one is to be consistent, then one has to also accept that, as well as impacting on participants in TLA research, structural and agentic factors will also impact on those who conduct the research. Thus, as there is no reason to believe that researchers have special immunity to the unconscious impact of social structures on their work, the 'cognitive unconscious' will impact on researchers into TLA as well on the academics and students who participate in their research. Therefore, if one is to take issues of 
structure and agency seriously, then one also needs to consider the role that the selections of researchers play in shaping the explanations that are generated through the research process.

In addition to the selection of research methods that was discussed in the previous section, it is in the selection of their research questions and approaches to data analysis that researchers most obviously shape the explanations that they construct through their research. Whilst the very idea of a cognitive unconscious suggests that it is not possible for individual researchers to have complete knowledge of all the structural and agentic factors that shape these selections, a commitment to accounting for structure and agency demands that one explain these decisions in writing up the research. However, such accounts are not common in the research into TLA in higher education.

First, in order to be able to form a research question, one needs to have theory that gives a sense of the possible relationships between the phenomena under investigation. As Silverman (2001, p.3) argues "without a theory there is nothing to research". So from the perspective of structure and agency, in order to understand how the researcher conceptualises their research, one needs to know the theoretical perspective that informs their research questions. However, the majority of research into TLA in higher education does not appear to do this. Tight's (2004) analysis of research into teaching and learning, course design and student experience in higher education outside of North America in 2000 suggested that only about a third of the studies showed any engagement with theoretical resources. 
Similarly, the approach that is taken to the process of turning raw data into analysed data plays a key role in shaping the explanations that are generated through the research process. The decision to focus on some aspects of the data and not others, as well as the ways in which the data are pooled and categorised, all shape what can be generated on the basis of those data. However in many research papers in TLA in higher education, through either the decisions of authors or editors, there is little or no account of how data were analysed by the researchers. Whilst, Tight (2000) does not provide figures on this, his finding that only about $40 \%$ of the papers he analysed gave an explicit account of their data collection methods suggests that a minority of papers in this area provide accounts of the approach taken to data analysis. Even where accounts of approaches to data are given, they are sometimes apparently meaningless statements of the form "the data were analysed vertically and horizontally, themes emerged and from these categories were generated". The absence of meaningful accounts of the approach taken to data analysis serves to conceal the role that the selections of the researcher have played in generating their findings. This sense of concealment is increased in interview studies in which individual quotations are used as evidence for a particular interpretation of a TLA interaction without any indication being given of how these particular quotations relate to the data set as a whole $^{2}$. This can give the impression that researchers have simply looked for aspects of their data that 'match' their conceptualisation of what is happening in the TLA interactions being studied and then reported these conceptualisations as the outcomes of their research.

\footnotetext{
${ }^{2}$ Although it should be noted that phenomenographic research, which is part of approaches to learning perspective, does relate individual quotations to the overall structure of the data. See Marton and Booth 1997, Åkerlind 2005, and Ashwin 2006 for a discussion of these issues.
} 
At best the absence of reflection by researchers on the theoretical origins of their research questions and the approach taken to data analysis limits the quality of explanations that are offered because it is not possible to examine the role that these selections have played in shaping the explanation that is offered. At worse it can lead to tautological research in which the implicit theory underpinning their research of TLA in higher education determines the research question and the outcomes of the research and is then given as the explanation of the aspect of TLA that has been investigated.

Once again, these are problems that are clearly identified in the research methods literature (for example, they are discussed in Silverman's (2001) 'eight reminders' of the potential of qualitative research), but they are seldom addressed in the literature on TLA in higher education. Thinking about how to account for structure and agency in higher education throws these issues into sharp relief and provides a focus that can help to improve the quality of explanations that are generated through this research.

\section{Conclusion}

In this paper I have argued that thinking about how to account for structure and agency in research into TLA in higher education raises important questions about this research. First it raises questions about what counts as an explanation in this research. Second, it raises questions about how the relationship between different units of analysis and between teaching, learning and assessment are conceptualised in this research. Finally, a consideration of how to account for structure and agency raises questions about the meaning of the data that is generated in such research, as well as 
the role that the selection of research questions and approaches to data analysis play in shaping the explanations that can be constructed on the basis this research.

In each case, a careful consideration of the implications of issues relating to structure and agency has questioned established ways in which research is approached, carried out and reported in this field. This suggests that explicit discussions of how structure and agency are accounted for in research into TLA in higher education can provide a useful starting point to improve the quality of explanations that are constructed in this area of educational research.

\section{Acknowledgements}

I would like to thank Monica McLean, Paul Trowler, Murray Saunders, Martyn Hammersley and participants at the Higher Education Close Up 3 Conference, Lancaster University, July 2006, for some very helpful discussions of the ideas contained in this paper.

\section{References}

Åkerlind, G.S. (2005). Variation and commonality in phenomenographic research methods. Higher Education Research and Development 24, 321-334.

Apple, M.W. (1979) Ideology and curriculum. London: Routledge and Kegan Paul.

Archer, L., Pratt, S., and Phillips, D. (2001) Working-class men's constructions of masculinity and negotiations of (non)participation in higher education. Gender and Education 13, 431-449. 
Archer, M. (1995) Realist social theory: The morphogenetic approach. Cambridge: Cambridge University Press.

Ashwin, P. (2006a) The development of learning and teaching in higher education: the changing context. In P.Ashwin (ed) Changing higher education: The development of learning and teaching. London: Routledge.

Ashwin, P. (2006b) Variation in academics' accounts of tutorials. Studies in Higher Education 31, 651-665.

Ashwin, P. (2005) Variation in students' experiences of the Oxford tutorial, Higher Education 50, $631-644$.

Avis, J., Bathmaker, A-M, and Parsons, J. (2002) Communities of practice and the construction of learners in post-compulsory education and training. Journal of Vocational Education and Training 54, 27 - 50.

Byrne, D. (1998) Complexity theory and the social sciences: An introduction. London: Routledge.

Bernstein, B. (1990) The structuring of pedagogic discourse. London: Routledge.

Bourdieu, P. (1992) The logic of practice. Translated by R. Nice. Cambridge: Polity Press.

Bourdieu, P. (1977) Outline of a theory of practice. Translated by R. Nice. Cambridge: Cambridge University Press.

Bourdieu, P. and Passeron. J-C. (1977) Reproduction in education, society and culture. Translated by R. Nice. London: Sage Publications.

Bourdieu, P., Passeron, J-C., and de Saint Martin, M. (1994) Academic discourse. Translated by R. Teese. Cambridge: Polity Press.

Chan, A. (2005) Policy discourses and changing practice: diversity and the university college. Higher Education 50, 129-157. 
Contu, A. and Willmott, H. (2003) Re-embedding situatedness: The importance of power relations in learning theory. Organization Science 14, 283-296.

Dibben, N. (2006) The socio-cultural and learning experiences of music students in a British university. British Journal of Music Education 23, 91 - 116.

Edwards, D. (1993) But what do children really think?: Discourse analysis and conceptual content in children's talk. Cognition and Instruction 11, 207 - 225.

Engeström, Y. (2001) Expansive learning at work: toward an activity theoretical reconceptualization. Journal of Education and Work 14, 133 - 156.

Fanghanel, J. (2004) Capturing dissonance in university teacher education environments. Studies in Higher Education 29, 576 - 590.

Fejes, A. , Johansson, K. and Abrandt, M. (2005) Learning to play the seminar game: students' initial encounters with a basic working form in higher education. Teaching in Higher Education 10, 29-40.

Fogel, M., Lyra, M. and Valsiner, J (1997) Dynamics and indeterminism in developmental and social processes. Mawah, New Jersey: Lawrence Erlbaum Associates.

Giddens, A. (1984) The constitution of society: Outline of the theory of structuration. Cambridge: Polity Press.

Haggis, T. (2003) Constructing images of ourselves? A critical investigation into 'approaches to learning' research in higher education. British Educational Research Journal 29, 89-104.

Haggis, T., (2004), Meaning, identity and 'motivation': Expanding what matters in understanding learning in higher education? Studies in Higher Education 29, $335-352$

Hammersley, M. (1992) What's wrong with ethnography? London: Routledge. 
Hammersley, M. (1999) Introduction. In M. Hammersley (ed) Researching School Experience: ethnographic studies of teaching and learning. London: Falmer Press.

Hymes, D. (1995) Bernstein and poetics. In P.Atkinson, B. Davies, and S. Delamont (eds) Discourse and reproduction: Essays in honour of Basil Bernstein. Cresskill, New Jersey: Hampton Press.

Jones, C., Turner, J. and Street B.V. (eds) (1999) Students writing in the university. Amsterdam/Philadelphia: John Benjamin's Publishing Company.

Jones, K., McLean, M., Amigoni, D. and Kinsman, M. (2005) Investigating the production of university English in mass higher education: an alternative methodology. Arts and Humanities in Higher Education 4, 247-264.

Kane, R., Sandretto, S. \& Heath, C. (2002) Telling Half the Story: A Critical Review of Research on the Teaching Beliefs and Practices of University Academics. Review of Educational Research 72 (2), 177-228.

Knight, P. and Saunders, M. (1999) Understanding teachers' professional cultures through interview: A constructivist approach. Evaluation and Research in Education 13, 144-156.

Layder, D. (1997). Modern social theory: Key debates and new directions. London: UCL Press.

Lave, J. and Wenger, E. (1991) Situated learning: Legitimate peripheral participation. Cambridge: Cambridge University Press.

Lea, M.and Street, B. (1998). Student writing in higher education: an academic literacies approach. Studies in Higher Education 23, 157- 172.

Lillis, T. (2001) Student writing: Access, regulation and desire. London: Routledge. 
Mann, S. (2000). The student's experience of reading. Higher Education 39, 297 317.

Mann, S. (2003) Inquiring into a higher education classroom: insights into the different perspective of teacher and students. In C. Rust (ed) Improving student learning: Theory and practice - 10 years on. Oxford: The Oxford Centre for Staff and Learning Development.

Marton, F. and Booth, S. (1997) Learning and awareness. Mawah, New Jersey: Lawrence Erlbaum Associates.

Mclean, M. (2006) Pedagogy and the university: Critical theory and practice. London: Continuum

Mouzelis, N. (1995) Sociological theory: What went wrong? London: Routledge.

Neumann, R. (2002) Disciplinary differences and university teaching. Studies in Higher Education 26, 135-146.

Neumann, R., Parry, S. and Becher, T. (2002) Teaching and learning in their disciplinary contexts: A conceptual analysis. Studies in Higher Education 27, $405-417$.

Peters, H. (2005) Contested discourses: Assessing the outcomes of learning from experience for the award of credit in higher education. Assessment and Evaluation in Higher Education 30, 273-285.

Price, M. (2005) Assessment standards: the role of communities of practice and the scholarship of assessment. Assessment and Evaluation in Higher Education 3, $215-230$.

Prosser, M. and Trigwell, K. (1999) Understanding learning and teaching: The experience in higher education. Buckingham: Society for Research into Higher Education and Open University Press. 
Read, B., Archer, L., and Leathwood, C. (2003) Challenging cultures? Student conceptions of 'belonging' and 'isolation' at a post-1992 university. Studies in Higher Education 28, $261-277$.

Richardson, J. (2005) Students' approaches to learning and teachers' approaches to teaching in higher education. Educational Psychology 25, 673-680.

Shay, S (2005) The assessment of complex tasks: A double reading. Studies in Higher Education 30 663-679.

Sibeon, R. (2004) Rethinking social theory. London: Sage Publications.

Silverman, D. (2001) Interpreting qualitative data. Second edition. London: Sage Publications.

Tight, M. (2003) Researching higher education. Buckingham: Society for Research into Higher Education and Open University Press.

Tight, M. (2004b). Research into higher education: An a-theoretical community practice? Higher Education Research and Development 23 (4), 395-411.

Tight, M. (2007) Bridging the divide: A comparative analysis of articles in higher education journals published inside and outside North America. Higher Education 53, 235-253.

Trowler, P. (1998) Academics responding to change: New higher education frameworks and academic cultures. Buckingham: Society for Research into Higher Education and Open University Press.

Trowler, P. (2005) A sociology of teaching, learning and enhancement: improving practices in higher education, Revista de Sociologia 76: 13-32

Trowler P. and Cooper, A. (2002). Teaching and learning regimes: implicit theories and recurrent practices in the enhancement of teaching and learning through 
educational development programmes. Higher Education Research and Development, 21, $221-240$.

Walker, M. (2005). Race is nowhere and race is everywhere: Narratives from black and white South African university students in post-apartheid South Africa. British Journal of Sociology of Education 26, 41-54.

Webb, G. (1997) Deconstructing deep and surface: Towards a critique of phenomenography. Higher Education 33, 195 - 212.

Wenger, E. (1998) Communities of practice: Learning, meaning and identity. Cambridge: Cambridge University Press.

Zimmerman, D. and Boden, D. (1991) Structure in action: an introduction. In D.Zimmerman and D. Boden (eds) Talk and Social Structure: Studies in Ethnomethodology and Conversation Analysis. Cambridge: Polity Press. 